NBER WORKING PAPER SERIES

\title{
BUYER INVESTMENT, PRODUCT VARIETY, AND INTRAFIRM TRADE
}

\author{
Yongmin Chen \\ Robert C. Feenstra \\ Working Paper 11752 \\ http://www.nber.org/papers/w11752
}

\author{
NATIONAL BUREAU OF ECONOMIC RESEARCH \\ 1050 Massachusetts Avenue \\ Cambridge, MA 02138 \\ November 2005
}

The authors thank Gary Hamilton, Misha Petrovic, and participants of the Spring 2005 NBER ITOWorking Group Meeting and of seminars at Hitotsubashi University and Waseda University for helpful comments, Bill Zeile for assistance with BEA data, and Chang Hong for research assistance. The views expressed herein are those of the author(s) and do not necessarily reflect the views of the National Bureau of Economic Research.

(C)2005 by Yongmin Chen and Robert C. Feenstra. All rights reserved. Short sections of text, not to exceed two paragraphs, may be quoted without explicit permission provided that full credit, including $\odot$ notice, is given to the source. 
Buyer Investment, Product Variety, and Intrafirm Trade

Yongmin Chen and Robert C. Feenstra

NBER Working Paper No. 11752

November 2005

JEL No. F1

\section{ABSTRACT}

This paper studies a simple model of buyer investment and its effect on the variety and vertical structure of international trade. A distinction is made between two types of buyer investment: "flexible" and "specific." Their interactions with the entry and pricing incentives of suppliers are analyzed. It is shown that (i) there can be multiple equilibria in the variety of products traded, and (ii) less product variety is associated with more intrafirm trade. The possibility of multiple equilibria is consistent with the observation that some similar economies, such as Taiwan and South Korea, differ substantially in their export varieties to the U.S. A formal empirical analysis confirms the negative correlation between product variety and intrafirm trade.

Yongmin Chen

University of Colorado, Boulder

yongmin.chen@colorado.edu

Robert C. Feenstra

Department of Economics

University of California

Davis, CA 95616

and NBER

rcfeenstra@ucdavis.edu 


\section{INTRODUCTION}

Recent literature in international trade has emphasized the importance of contractual relationships between firms, and sought to explain these contractual relations by features of the industries and host countries. For example, Antràs (2003) argues that in more capitalintensive industries, a greater share of trade is intrafirm, i.e. between a parent and its subsidiaries. Antràs and Helpman (2003) analyze a more general multi-industry, multicountry model, where the type of contracts and ownership between firms will depend on features of the industry (the productivity distribution of firms) as well as features of the host countries (such as factors prices). Similarly, Nocke and Yeaple (2004) solve for the locational choice of foreign direct investment (FDI) by matching characteristics of the companies and the host countries.

Missing from this literature, however, is a consideration of the buyers in the destination market. Gary Gereffi (1994; Gereffi and Lin 1994) uses the term "big buyers" to refer to the mass merchandisers in the United States who, he argues, have influenced the organization of production in Asia. As a specific example, consider South Korea and Taiwan. While these two economies export in many of the same broad industry categories, the details of their trade are quite different. South Korea is well-known for trying to achieve "world status" in products such as cars, microwaves, consumer electronics, dynamic random access memories (DRAMs) and other mass-produced goods. The business groups selling these goods - such as Hyundai, Samsung and Daewoo - have become household names in the U.S. and worldwide. Taiwan, by contrast, focuses more on intermediate inputs and customized products, selling auto parts and bicycles rather than cars, more customized chips than DRAMs, women's fashions as opposed to men's shirts, etc. Many of these goods are produced under OEM (original equipment manufacturer) arrangements for retailers overseas, who typically require customized designs. This is one explanation for the finding that Taiwan exports a great variety of products to the U.S. than does South Korea in many industries (Feenstra, Yang, 
and Hamilton, 1999).

Feenstra and Hamilton (2004) have recently argued that the differential export patterns from South Korea and Taiwan are at least in part the result of increased demand generated by regulatory changes in the United States. Specifically, the repeal of "fair trade laws" in the United States during the 1960s allowed for huge increase in mass-merchandising, orchestrated by the merchandisers acting as intermediaries between U.S. consumers and Asian producers. This increase in U.S. demand occurred just as Korea and Taiwan were in a position to meet that demand; but that it was exercised in different market segments within the two countries. Buyers began to look to Korea for the provision of long production runs of relatively standardized products, whereas Taiwan supplied shorter production runs of more specialized, niche products. Thus, the exercise of international demand resulted in quite different product varieties from each country.

To examine this hypothesis, we propose a simple model of how buyers can influence product variety. In particular, we consider how buyer investment in input requirements can affect the variety and vertical structure of trade for intermediate goods. The recent literature on the organization of international trade tends to focus on situations where sellers make investments (e.g., McLaren, 2000; Antràs, 2003); ${ }^{1}$ our focus on buyer investment complements this literature. Our basic model, described in section 2, is the familiar circle of product varieties, with upstream suppliers arranging themselves at discrete intervals. Downstream buyers have preferred specifications of the good, but can incur an investment allowing them to more easily adapt to different specifications that are not their preferred. Such "flexible" investment, however, reduces the incentives for upstream entry and results in fewer upstream varieties. This tension between upstream variety and downstream flexibility can give rise to multiple equilibria in the economic organization: more (or all) downstream buyers make flexible investment and upstream suppliers produce fewer varieties; or fewer

\footnotetext{
${ }^{1}$ Models in the theory of contracts and firms also tend to focus more on the investment incentives of the sellers, but investment incentives by buyers clearly have also received attention, as, for instance, in the general framework of Grossman and Hart (1986), and in the empirical work of Joskow (1987) where downstream power plants can make asset-specific investment by locating closer to coal mines.
} 
(or no) downstream buyers make flexible investment and upstream suppliers produce more varieties. $^{2}$ One interesting implication of this model is that it provides an explanation for the different export market structures of South Korea and Taiwan, if we interpret an equilibrium with fewer varieties as applying to Korea, and an equilibrium with more varieties as applying to Taiwan.

In Section 3, we extend the basic model by allowing each downstream buyer to have the additional option of making a "specific" investment that would match its preferred specification with a particular supplier's (i.e., increasing the buyer's match quality with the supplier). In an equilibrium with more varieties, a buyer can expect its input needs to be matched relatively well by a supplier, and thus there is less benefit to make the specific investment ex ante; the opposite is true in an equilibrium with fewer varieties. As it turns out, more buyers can potentially benefit from the specific investment in an equilibrium with fewer varieties. However, there is an important distinction between a buyer's specific investment and flexible investment: while the flexible investment reduces suppliers' market power, the specific investment increases their market power and can create the familiar hold-up problem. Vertical integration between buyers and suppliers can serve as a mechanism to overcome the hold-up problem and realize the gains from specific investment. Consequently, in an equilibrium with fewer varieties, where the gains from specific investment are higher, there is more vertical integration, or more intrafirm trade. The consideration of the two types of buyer investment, and of their interactions with the entry and pricing incentives of suppliers, can thus lead to an equilibrium theory of variety and vertical structure in international trade. The central prediction of this theory is that there is a negative correlation between variety and intrafirm trade.

At an aggregate level, we know that this prediction is true for South Korea and Taiwan: Zeile (2003, Table 2B) reports that for U.S. imports in 1997, only $9.8 \%$ of goods coming from Taiwan were intrafirm purchases from their foreign parent groups, whereas $32.8 \%$ of

\footnotetext{
${ }^{2}$ When the cost for flexible investment is sufficiently low or sufficiently high, there is a unique equilibrium where either all buyers invest or no buyer does, respectively.
} 
goods coming from Korea where intrafirm purchases. ${ }^{3}$ The goal of our empirical work in Sections 4-6 is to explore this connection between product variety and intrafirm trade for a broader sample of countries. Our empirical analysis uses two closely related approaches. Our first approach builds on Antràs (2003), who finds that countries with more capitalintensive exports are more likely to engage in intra-firm trade across borders. Along with capital intensity and in a larger data set, we add the U.S. import variety from various countries as an explanatory variable, ${ }^{4}$ or more precisely, the unexplained portion of import variety from that predicted from a gravity equation. We find that this variable is negatively correlated with intrafirm trade, as expected from our theory. In our second approach, we include control variables for country size, distance, etc. simultaneously with estimating the relationship between product variety and intrafirm trade, and again find support for the negative relationship. Conclusions and directions for further research are discussed in Section 7 .

\section{THE BASIC MODEL}

There are two countries, home $(H)$ and foreign $(F)$. There is a continuum of $M$ firms in $H$, each of which needs to purchase 1 unit of an input from $F$. Each home firm's input has an ideal characteristic that is represented by a point on a circle of unit perimeter length. In purchasing the input, the firm incurs an adjustment cost that is the product of $\tau$ and the distance between its ideal point and the location of its supplier along the circle. Thus $\tau$ is the unit adjustment (transportation) cost, which is a measure of how flexible the downstream firm is in its input requirement (or how easily the downstream firm can substitute its input between different suppliers). A downstream firm can invest $(I)$ to increase the flexibility of

\footnotetext{
${ }^{3}$ For the 1992 benchmark survey (Zeile, 1997, Table 6) reports that $4.5 \%$ of the goods coming from Taiwan were intra-firm purchases from their foreign parent groups, whereas $21 \%$ of the goods coming from Korea were intra-firm purchases. Evidently, the extent of intra-firm exports from both Taiwan and Korea has been growing.

${ }^{4}$ As in Antràs (2003), we examine these contries' exports to the U.S., and thus the variable is the same as the U.S. import variety from these countries.
} 
its input requirement. In particular, we assume:

$$
\tau=\left\{\begin{array}{ccc}
\tau_{h} & \text { if } & I=0 \\
\tau_{l} & \text { if } & I=k>0
\end{array},\right.
$$

where $0<\tau_{l}<\tau_{h}$. For instance, $k$ could be an investment in a technology that allows greater input substitutability. Alternatively, $k$ may be an investment that reduces transaction costs with potential suppliers, such as setting up an office in $F .^{5}$ Ex ante, each firm's ideal point is a random variable uniformly distributed on the circle. Downstream firms in $H$ will also be called buyers.

There are a large number of potential suppliers (upstream firms) in the foreign country. Each of them can choose to enter the market with entry cost $f>0$ and produce the input with constant marginal cost $c \geq 0$. The game, in which only pure strategies will be considered, is as follows:

- Stage 1. Potential suppliers simultaneously make entry decisions, and choose locations on the circle if entry occurs.

- Stage 2. Each downstream firm in $H$ decides whether to invest $k$ to increase its flexibility in dealing with different suppliers.

- Stage 3. The downstream firms' locations (ideal points) on the circle are realized. The suppliers who have entered the market, observing downstream firms' locations and whether they have invested $k$, simultaneously bid prices to the downstream firms.

- Stage 4. Each downstream firm accepts the offer with the lowest purchasing cost (price plus adjustment cost), and the input is produced. ${ }^{6}$

We start our analysis by considering the situation where $n \geq 2$ suppliers are located on the circle with equal distance from each other. Without loss of generality, we let supplier

\footnotetext{
${ }^{5}$ The investment could also be on the organization/marketing of production. If the downstream firms are retailers, for instance, by investing in large discount stores (shopping malls) and adopting mass retailing, the downstream firms may desire more standardized products with lower costs.

${ }^{6}$ The downstream firms are assumed to value the input sufficiently high so that the input is always purchased in equilibrium.
} 
1 be located at the bottom of the circle and number suppliers and buyers in the clockwise order. A buyer's location is characterized by $x_{i}$, which means that the buyer is located immediately ahead of supplier $i$ and its distance from $i$ is $x_{i}$. We denote supplier $i$ by $U i$.

Given any $\tau \in\left\{\tau_{h}, \tau_{l}\right\}$, any $x_{i}$ will effectively face two competing suppliers, $i$ and $i+1$ for $i=1, \ldots, n-1$, or $i$ and 1 for $i=n$. The marginal customer for supplier $i$ is $x_{i}=\frac{1}{2 n}$. If $x_{i}<\frac{1}{2 n}$, supplier $i$ has a competitive advantage in serving $x_{i}$ and will supply $x_{i}$ at price $p_{i}$, where

$$
p_{i}+\tau x_{i}=c+\tau\left(\frac{1}{n}-x_{i}\right) .
$$

The Bertrand-Nash equilibrium price of firm $i$ for buyer $x_{i}$ is:

$$
p_{i}\left(x_{i}\right)=\max \left\{c, c+\tau\left(\frac{1}{n}-2 x_{i}\right)\right\} .
$$

If portion $\alpha \in[0,1]$ of buyers have $\tau_{h}$ (investing no $k$ ), and portion $1-\alpha$ of buyers have $\tau_{l}$ (investing $k$ ), we assume that each portion will be uniformly distributed on the circle, same as the entire buyer population. Supplier $i$ 's equilibrium profit, taking into account the potential buyers on its right side as well, is thus

$$
\begin{aligned}
\pi_{i} & =M\left[\alpha 2 \int_{0}^{\frac{1}{2 n}}\left(c+\tau_{h}\left(\frac{1}{n}-2 x_{i}\right)-c\right) d x_{i}+(1-\alpha) 2 \int_{0}^{\frac{1}{2 n}}\left(c+\tau_{l}\left(\frac{1}{n}-2 x_{i}\right)-c\right) d x_{i}\right]-f \\
& =M \frac{1}{2 n^{2}}\left(\alpha \tau_{h}+(1-\alpha) \tau_{l}\right)-f .
\end{aligned}
$$

In a free-entry (zero-profit) equilibrium, we have

$$
\hat{n}=\sqrt{M \frac{\hat{\tau}}{2 f}}
$$

where $\hat{\tau} \equiv \alpha \tau_{h}+(1-\alpha) \tau_{l}$. We assume $M \geq \frac{8 f}{\tau_{l}}$, which ensures $\hat{n} \geq 2$.

A buyer's expected price when there are $n$ suppliers is

$$
2 n \int_{0}^{\frac{1}{2 n}} p_{i}\left(x_{i}\right) d x_{i}=2 n \int_{0}^{\frac{1}{2 n}}\left(c+\tau\left(\frac{1}{n}-2 x_{i}\right)\right) d x_{i}=c+\frac{\tau}{2 n} .
$$

The buyer's expected cost of purchasing the input when there are $n$ suppliers is

$$
2 n \int_{0}^{\frac{1}{2 n}}\left(p_{i}\left(x_{i}\right)+\tau x_{i}\right) d x_{i}=2 n \int_{0}^{\frac{1}{2 n}}\left(c+\tau\left(\frac{1}{n}-2 x_{i}\right)+\tau x_{i}\right) d x_{i}=c+\frac{3 \tau}{4 n}
$$


We next provide the justification for our focus on an upstream market structure in which all suppliers have the same distance from each other, with the following result concerning the location choices of suppliers at any subgame perfect equilibrium of the game:

Lemma 1 In equilibrium, all suppliers must be equally distanced from each other.

Proof. We consider the two cases where $n=2$ and $n \geq 3$ separately.

Case 1: $n=2$. Suppose first that U2's distance from U1 is $y \leq \frac{1}{2}$ clockwise. For any consumer $x_{1}$ and $x_{2}$ of given $\tau$, the equilibrium prices of $\mathrm{U} 2$ are

$$
\begin{aligned}
& p_{2}\left(x_{1}\right)=\max \left\{c, c+\tau\left(2 x_{1}-y\right)\right\}, \\
& p_{2}\left(x_{2}\right)=\left\{\begin{array}{ccc}
c+\tau y & \text { if } 0 \leq x_{2} \leq \frac{1}{2}-y \\
\max \left\{c, c+\tau\left(1-y-2 x_{2}\right)\right\} & \text { if } \quad \frac{1}{2}-y<x_{2} \leq \frac{1-y}{2}
\end{array} .\right.
\end{aligned}
$$

U2's profit is the same as U1's and is equal to

$$
\begin{aligned}
\pi(y)= & M \int_{\frac{y}{2}}^{y}\left(c+\hat{\tau}\left(2 x_{1}-y\right)-c\right) d x_{1}+M \int_{0}^{\frac{1}{2}-y}(c+\hat{\tau} y-c) d x_{2} \\
& +M \int_{\frac{1}{2}-y}^{\frac{1-y}{2}}\left(c+\hat{\tau}\left(1-y-2 x_{2}\right)-c\right) d x_{2} \\
= & -\frac{1}{2} M y^{2} \hat{\tau}+\frac{1}{2} M y \hat{\tau}
\end{aligned}
$$

where recall $\hat{\tau}=\alpha \tau_{h}+(1-\alpha) \tau_{l}$. Thus

$$
\pi^{\prime}(y)=-M \hat{\tau} y+\frac{1}{2} M \hat{\tau}
$$

and hence in equilibrium $y$ must be

$$
y^{*}=\frac{1}{2}
$$

Similar $y^{*}=\frac{1}{2}$ if we assume $y \geq \frac{1}{2}$.

Case 2: $n \geq 3$. Suppose that the distance of supplier $i+1$ to $i$ is $y$, and its distance to supplier $i+2$ is $l-y$. It suffices to show that in equilibrium $y=\frac{l}{2}$, since this would imply that there can be no equilibrium where suppliers are not located in equal distance to each other, and furthermore by letting $l=\frac{2}{n}$ it is an equilibrium for firms to locate in equal distance to each other. 
With reasoning similar to that in Case 1 , we can assume $y \leq \frac{l}{2}$ and write the equilibrium profit of supplier $i+1$ as

$$
\begin{aligned}
\pi_{i+1}(y)= & M \int_{\frac{y}{2}}^{y}(c+\hat{\tau}(2 x-y)-c) d x+M \int_{0}^{\frac{l}{2}-y}(c+\hat{\tau} y-c) d x \\
& +M \int_{\frac{l}{2}-y}^{\frac{l-y}{2}}(c+\hat{\tau}(l-y-2 x)-c) d x \\
= & -\frac{1}{2} M y^{2} \hat{\tau}+\frac{1}{2} M \hat{\tau} l y
\end{aligned}
$$

Thus

$$
\pi_{i+1}^{\prime}(y)=-M y \hat{\tau}+\frac{1}{2} M \hat{\tau} l
$$

and hence in equilibrium $y^{*}=\frac{l}{2}$.

We are now ready to establish the main result of the basic model. Define

$$
\begin{aligned}
\bar{k} & \equiv \frac{3}{4} \frac{\tau_{h}-\tau_{l}}{n_{l}}, \quad \underline{k} \equiv \frac{3}{4} \frac{\tau_{h}-\tau_{l}}{n_{h}}, \\
\alpha_{m} & \equiv \frac{\tau_{l}}{\left(\tau_{h}-\tau_{l}\right)}\left(\left(\frac{\bar{k}}{k}\right)^{2}-1\right) \in(0,1) \text { for } k \in(\underline{k}, \bar{k}), \\
\tau_{m} & \equiv \alpha_{m} \tau_{h}+\left(1-\alpha_{m}\right) \tau_{l}, \\
n_{j} & \equiv \sqrt{\frac{M \tau_{j}}{2 f}} \quad \text { for } j=h, m, l .
\end{aligned}
$$

Then, since $\tau_{l}<\tau_{m}<\tau_{h}$, we have $n_{l}<n_{m}<n_{h}$.

Proposition 1 For the basic model:

(1) If $k>\bar{k}$, the unique equilibrium is $I^{*}=0\left(\tau^{*}=\tau_{h}\right)$ for all buyers and $n^{*}=n_{h}$.

(2) If $k<\underline{k}$, the unique equilibrium is $I^{*}=k\left(\tau^{*}=\tau_{l}\right)$ for all buyers and $n^{*}=n_{l}$.

(3) If $\underline{k} \leq k \leq \bar{k}$, there are three and only three equilibria: (i) $I^{*}=0$ ( $\tau^{*}=\tau_{h}$ ) for all buyers and $n^{*}=n_{h}$; (ii) $I^{*}=k\left(\tau^{*}=\tau_{l}\right)$ for all buyers and $n^{*}=n_{l}$; and (iii) for $\underline{k}<k<\bar{k}$, $I^{*}=0\left(\tau^{*}=\tau_{h}\right)$ for $\alpha_{m}$ buyers while $I^{*}=k\left(\tau^{*}=\tau_{l}\right)$ for $\left(1-\alpha_{m}\right)$ buyers, and $n=n_{m}$.

Proof. First, from Lemma 1, suppliers will locate in equal distance from each other in equilibrium.

Second, if $I=0$ and hence $\tau=\tau_{h}$ for all buyers, then $n=n_{h}$ from the derivation of $\hat{n}$ given in equation (1) and the definition of $n_{h}$. Thus it is an equilibrium for all buyers to 
choose $I^{*}=0$ with $n^{*}=n_{h}$ if and only if, given $n_{h}$, no buyer can benefit from investing $k$, or

$$
c+\frac{3 \tau_{h}}{4 n_{h}}-\left(c+\frac{3 \tau_{l}}{4 n_{h}}+k\right) \leq 0
$$

or $k \geq \frac{3}{4} \frac{\tau_{h}-\tau_{l}}{n_{h}} \equiv \underline{k}$.

Third, if $I=k$ and hence $\tau=\tau_{l}$ for all buyers, then $n=n_{l}$ from the derivation of $\hat{n}$ given in equation (1) and the definition of $n_{l}$. Thus it is an equilibrium for all buyers to choose $I^{*}=k$ with $n^{*}=n_{l}$ if and only if, given $n_{l}$, no buyer can benefit from investing 0 , or

$$
\frac{3 \tau_{l}}{4 n_{l}}+k \leq \frac{3 \tau_{h}}{4 n_{l}}
$$

That is, $k \leq \frac{3}{4} \frac{\tau_{h}-\tau_{l}}{n_{l}} \equiv \bar{k}$.

Fourth, since $n_{l}<n_{h}$, we can divide $k$ into the three mutually exclusive intervals. If $k>\bar{k}$, it is an equilibrium for all buyers to choose $I^{*}=0$ with $n^{*}=n_{h}$; and there can be no other equilibrium for the following reason: If there were another equilibrium, some buyers must choose $I=k$ at this equilibrium, and thus the equilibrium number of firms would be $\tilde{n} \in\left[n_{l}, n_{h}\right)$. But then any buyer choosing $I=k$ cannot be optimizing since for $k>\bar{k}$

$$
\left(c+\frac{3 \tau_{h}}{4 \tilde{n}}\right)-\left(c+\frac{3 \tau_{l}}{4 \tilde{n}}+k\right)=\frac{3}{4} \frac{\tau_{h}-\tau_{l}}{\tilde{n}}-k<\frac{3}{4} \frac{\tau_{h}-\tau_{l}}{\tilde{n}}-\bar{k} \leq \frac{3}{4} \frac{\tau_{h}-\tau_{l}}{n_{l}}-\bar{k}=0 .
$$

Thus, if $k>\bar{k}$, the unique equilibrium is $I^{*}=0$ for all buyers and $n^{*}=n_{h}$.An analogous argument establishes that, if $k<\underline{k}$, the unique equilibrium is $I^{*}=k$ for all buyers and $n^{*}=n_{l}$.

Finally, to establish Part (3) of the proposition, we notice that (i) and (ii) follow immediately from the second and third steps above. It is also clear that there can be no other equilibrium where all buyers choose $I=k$ or none does. Thus, our proof will be complete if (iii) holds and it gives the only equilibrium where some buyers invest $k$ and others do not. Notice that if in equilibrium some buyers invest $k$ and others do not, the buyers must have the same expected procurement cost from investing $k$ or 0 ; that is

$$
\frac{3 \tau_{h}}{4 n}=\frac{3 \tau_{l}}{4 n}+k
$$


On the other hand, for any $\alpha$, free entry in the upstream market requires that in equilibrium

$$
n^{2}=M \frac{1}{2 f}\left(\alpha \tau_{h}+(1-\alpha) \tau_{l}\right)
$$

These two simultaneous equations are uniquely solved by $\alpha=\alpha_{m} \equiv \frac{\tau_{l}}{\left(\tau_{h}-\tau_{l}\right)}\left(\left(\frac{\bar{k}}{k}\right)^{2}-1\right)$ and $n=n_{m} \equiv \sqrt{\frac{M \tau_{m}}{2 f}}$, where $\alpha_{m}=0$ if $k=\bar{k}, \alpha_{m}=1$ if $k=\underline{k}$, and $0<\alpha_{m}<1$ for $\underline{k}<k<\bar{k}$. Therefore it is indeed an equilibrium that $I^{*}=0$ for $\alpha_{m}$ buyers, $I^{*}=k$ for $\left(1-\alpha_{m}\right)$ buyers, and $n=n_{m}$; and there can be no other equilibrium where some buyers invest $k$ and others do not.

Thus, for similar economies, there can be rather different market structures in their exports: some with a relatively large number of small suppliers, each producing a small quantity; and others with a smaller number of larger suppliers, each producing a larger quantity. This provides an explanation of the different market structures of export sectors in South Korea and Taiwan. When buyers become more flexible in their input requirements, there are less incentive for variety and more incentive for lowering average cost in the upstream industry. This seems to be the case for Korea, where buyers from the US looked for long production runs of relatively standardized products. In the case for Taiwan, international buyers appeared to have demanded shorter production runs of more specialized, niche products; and this provides incentive for more upstream entry and the provision of more varieties. Our analysis captures an interesting tension between upstream variety and downstream flexibility, which has not been noticed in the literature before.

While the circle model is well known in the product differentiation literature, ours has two distinctive features, namely $\tau$ can be changed through investment and the locations of buyers are observed by sellers in price competition. These features seem especially natural in the intermediate-goods market, where the identities of buyers are usually known by suppliers, and where a buyer is likely to be able to invest in technologies or to make arrangements that affect the cost to change suppliers. ${ }^{7}$ Our analysis would be similar if the locations of the

\footnotetext{
${ }^{7}$ The considerations here are related to the approach in Chen (forthcoming), who studies the incentives for, and effects of, marketing innovations by producers of final goods that increase their abilities to gather consumer information or reduce consumer transaction costs.
} 
downstream firms were not observable, but then the equidistant locations of the suppliers would need a justification that is different from our proof for Lemma $1 .^{8}$ An advantage of our formulation is that the location choices of firms (locating equidistantly) is established as the equilibrium outcome of the game with linear transportation cost.

We can shed some light on the welfare property of the equilibrium choice of $I$. The expected procurement cost of any downstream firm is given by

$$
z=\left\{\begin{array}{ccc}
c+\frac{3 \tau_{h}}{4 n_{h}} & \text { if } & I^{*}=0 \text { for all buyers and } n^{*}=n_{h} \\
c+\frac{3 \tau_{h}}{4 n_{m}}=c+\frac{3 \tau_{l}}{4 n_{m}}+k & \text { if } \quad \alpha_{m} \text { buyers choose } I^{*}=k \text { and } n^{*}=n_{m} \\
c+\frac{3 \tau_{l}}{4 n_{l}}+k & \text { if } \quad \text { all buyers choose } I^{*}=k \text { and } n^{*}=n_{l}
\end{array}\right.
$$

If buyers were able to act jointly in committing to an $I$ in the beginning of the game, then it would be optimal for them to choose $I=0$ if

$$
c+\frac{3 \tau_{h}}{4 n_{h}} \leq c+\frac{3 \tau_{l}}{4 n_{l}}+k
$$

or $k>\frac{3 \tau_{h}}{4 n_{h}}-\frac{3 \tau_{l}}{4 n_{l}}$, and to choose $I=k$ if

$$
k \leq \frac{3 \tau_{h}}{4 n_{h}}-\frac{3 \tau_{l}}{4 n_{l}}
$$

And, since $c+\frac{3 \tau_{h}}{4 n_{m}}>c+\frac{3 \tau_{h}}{4 n_{h}}$ due to $n_{m}<n_{h}$, it would not be optimal for some buyers to choose $I=k$ and the others to choose $I=0$. Notice that

$$
\underline{k}-\left(\frac{3 \tau_{h}}{4 n_{h}}-\frac{3 \tau_{l}}{4 n_{l}}\right)=\frac{3}{4} \frac{\tau_{h}-\tau_{l}}{n_{h}}-\left(\frac{3 \tau_{h}}{4 n_{h}}-\frac{3 \tau_{l}}{4 n_{l}}\right)=\frac{3 \tau_{l}}{4}\left(-\frac{1}{n_{h}}+\frac{1}{n_{l}}\right)>0 .
$$

Hence, if the procurement cost is lower with $I=k$, or $k \leq \frac{3 \tau_{h}}{4 n_{h}}-\frac{3 \tau_{l}}{4 n_{l}}$, we must also have $k<\underline{k}$ and in equilibrium $I^{*}=k$. But if the procurement cost is lower with $I=0$, or $k>\frac{3 \tau_{h}}{4 n_{h}}-\frac{3 \tau_{l}}{4 n_{l}}$, it is still possible that in equilibrium $I^{*}=k$. This inefficient "over-investment" by the buyers occurs as the unique equilibrium outcome if $\frac{3 \tau_{h}}{4 n_{h}}-\frac{3 \tau_{l}}{4 n_{l}}<k<\underline{k}$, and can occur as one of the equilibria if $\underline{k} \leq k \leq \bar{k}$. We therefore have:

\footnotetext{
${ }^{8}$ To our knowledge, in the literature on product differentiation, the equidistant result in the circle model has been shown as the equilibrium of a location game only with quadratic transportation costs.
} 
Corollary 1 In equilibrium, buyers' choice of $I^{*}$, the input flexibility investment, minimizes their procurement cost if

$$
\text { either } k \leq \frac{3 \tau_{h}}{4 n_{h}}-\frac{3 \tau_{l}}{4 n_{l}} \text { or } k>\bar{k} .
$$

Otherwise $I^{*}=k$ can occur in equilibrium but buyers' procurement costs are not minimized.

Interestingly, while the ability to invest in the flexibility of input requirements can benefit the buyers, sometimes it also makes them worse off. Such investment intensifies competition among any given number of suppliers and reduces the rents needed to cover their entry costs. For fear of this, there will be less entry of suppliers, resulting in less variety in the intermediate-goods market and less competition there, which makes it indeed desirable for the buyers to invest in input flexibility. The inefficiency arises since the flexible investment by the buyers has a negative externality on the suppliers, which the buyers do not internalize. In equilibrium, the suppliers correctly anticipate this and reduce entry. The problem is that buyers cannot collectively commit not to invest $k$. Such commitment, for instance, would not be possible if contracting for $k$ is not feasible.

\section{SPECIFIC INVESTMENT AND VERTICAL STRUCTURE}

In our basic model, the upstream and downstream firms are by assumption independently owned. We now extend the basic model to allow the vertical structure in international trade to be determined endogenously, so that in equilibrium some firms may be vertically integrated. We modify Stage 2 of the basic model as follows: At Stage 2, each buyer first learns to which supplier it is located closest (or, equivalently, which one of the segments of length $\frac{1}{2 n}$ on the circle it belongs to), even though its precise location is not realized until Stage 3. We shall call an upstream firm the favored supplier of the downstream firms to which it is located closest. Second, each buyer can invest $s$ to position its ideal point at the location of its favored supplier, ${ }^{9}$ where $s$ is the realization of a continuous random variable

\footnotetext{
${ }^{9}$ This is a crude way of introducing the idea that a buyer can invest to increase her match quality with a supplier, for instance, through adjusting its input requirement, adopting a particular technology, providing specific employee training, or marketing efforts promoting the supplier's product.
} 
with c.d.f. $G(s)$ on support $[\underline{s}, \bar{s}]$, and we assume $0<\underline{s} \leq \frac{\tau_{h}}{4 n_{h}}<\frac{\tau_{l}}{4 n_{l}}+k<\bar{s}$. ${ }^{10}$ Third, the supplier is unable to commit to any price that it will charge the buyer, but it can vertically integrate with the buyer. ${ }^{11}$ Fourth, the buyer can still invest $k$ if it wishes. Everything else in this extended model is the same as in the basic model.

It is immediately clear that, if no buyer invests $s$, the analysis and the equilibrium of the game will be exactly the same as in the previous section. In particular, since the expected procurement cost for any buyer on any of the segments of length $\frac{1}{2 n}$ is the same, knowing which segment it belongs to will not change the buyer's decision on whether or not to invest $k$.

If in equilibrium $n^{*}=n_{l}$, then the expected procurement cost of a buyer without investing $s$ (but investing $k$ ) is $c+\frac{3 \tau_{l}}{4 n_{l}}+k$, and its supplier expects to receive from it

$$
2 n_{l} \int_{0}^{\frac{1}{2 n_{l}}}\left(p_{i}\left(x_{i}\right) d x_{i}-c\right) \text {. }
$$

If

$$
s+c<c+\frac{3 \tau_{l}}{4 n_{l}}+k-2 n_{l} \int_{0}^{\frac{1}{2 n_{l}}}\left(p_{i}\left(x_{i}\right) d x_{i}-c\right)=c+\frac{\tau_{l}}{4 n_{l}}+k
$$

or

$$
s<\frac{\tau_{l}}{4 n_{l}}+k \equiv s_{1}
$$

then investing $s$ (and not investing $k$ ) will lead to a higher joint surplus between this pair of buyer and supplier. However, if the buyer invests $s$, it will be subject to the well-known hold-up problem since the supplier has not committed to its price. Because the buyer making the specific investment will be further away from other suppliers, it expects to pay a higher price ex post. Thus, absent of vertical integration, $s$ will not be invested. Vertical

\footnotetext{
${ }^{10}$ The assumption that $\frac{\tau_{h}}{4 n_{h}}<\frac{\tau_{l}}{4 n_{l}}+k$ will not be needed if we are only concerned with multiple equilibria for the same industry. For comparisons of different industries, this assumption ensures that $k$ is not too small relative to $\left(\sqrt{\tau_{h}}-\sqrt{\tau_{l}}\right)$. It can be easily verified that $\underline{k}>\frac{1}{4}\left(\frac{\tau_{h}}{n_{h}}-\frac{\tau_{l}}{n_{l}}\right)$.

${ }^{11}$ We assume that vertical integration can possibly occur only if at least one party strictly benefits from it, even though for simplicity we assume that there is no additional cost associated with vertical integration. We can easily add a cost for vertical integration and reduce $s$ by this cost, without changing the result of our analysis.
} 
integration can solve this hold-up problem and realize the potential gains from the specific investment. With vertical integration, for convenience we assume that the downstream firm makes a take-it-or-leave-it offer to the upstream firm, and we allow two possible processes of vertical integration between downstream firms and their favored supplier: In the first case, one downstream firm purchases the upstream firm while the other integrating downstream firms sell their businesses to the upstream firm, resulting in a vertically integrated firm that is owned by a buyer. In the second case, all vertically integrating downstream firms sell their businesses to their favored supplier, resulting in a vertically integrated firm that is owned by the supplier. ${ }^{12}$ Under either case, vertical integration will not change the expected earnings of the upstream firms and hence not the equilibrium number of upstream producers, because the upstream firm's expected payoff from each merging downstream firm will be

$$
\tilde{\pi}_{i}=\int_{0}^{\frac{1}{2 n}}\left(p_{i}\left(x_{i}\right)-c\right) 2 n d x_{i}=\int_{0}^{\frac{1}{2 n}}\left(c+\tau_{l}\left(\frac{1}{n_{n}}-2 x_{i}\right)-c\right) 2 n_{l} d x_{i}=\frac{\tau_{l}}{2 n_{l}},
$$

which is the same as its expected earnings from any downstream firm who is within the $\frac{1}{2 n_{l}}$ distance and who does not invest $s$ (but invests $k$, consistent with $n^{*}=n_{l}$ ). Therefore, if in equilibrium $n^{*}=n_{l}$, a mass of $M G\left(s_{1}\right)$ buyers will vertically integrate with suppliers, or $M G\left(s_{1}\right)$ amount of $H^{\prime} s$ imports from $F$ will be intrafirm imports.

Next, if in equilibrium $n=n_{m}$, which can occur for any $k \in(\underline{k}, \bar{k})$, then the expected procurement cost of a downstream firm without investing $s$ is

$$
c+\frac{3 \tau_{h}}{4 n_{m}}=c+\frac{3 \tau_{l}}{4 n_{m}}+k
$$

An upstream firm's expected payoff from each merging downstream firm will be

$$
\tilde{\pi}_{i}=\int_{0}^{\frac{1}{2 n}}\left(\alpha_{m}\left(c+\tau_{h}\left(\frac{1}{n_{m}}-2 x_{i}\right)\right)+\left(1-\alpha_{m}\right)\left(c+\tau_{l}\left(\frac{1}{n_{m}}-2 x_{i}\right)\right)-c\right) 2 n_{m} d x_{i}=\frac{\tau_{m}}{2 n_{m}}
$$

Vertical integration (together with investing $s$ by a downstream firm) will occur if and only

\footnotetext{
${ }^{12}$ For our purpose, we do not consider the issue of how ownership rights should be assigned within a firm. We simply assume that vertical integration solves, or at least alleviates, the hold-up problem. However, the propety rights approach (e.g., Grossman and Hart, 1986) has suggested that the ownership rights should be assigned to the party that makes the investment, which, in our case here, is the buyer.
} 
if

$$
s+c<c+\frac{3 \tau_{l}}{4 n_{m}}+k-\left(\frac{\tau_{m}}{2 n_{m}}\right)=c+\frac{3 \tau_{l}}{4 n_{m}}+k-\frac{\tau_{m}}{2 n_{m}},
$$

or

$$
s<\frac{3 \tau_{l}-2 \tau_{m}}{4 n_{m}}+k \equiv s_{2} .
$$

Thus, if in equilibrium $n^{*}=n_{m}$, a mass of $M G\left(s_{2}\right)$ buyers will vertically integrate with suppliers, or $M G\left(s_{2}\right)$ amount of $H^{\prime} s$ imports from $F$ will be intrafirm imports. Note that $s_{2}=\frac{3 \tau_{l}-2 \tau_{m}}{4 n_{m}}+k=\frac{3 \tau_{h}-2 \tau_{m}}{4 n_{m}}$ for any $k \in(\underline{k}, \bar{k})$.

Finally, if in equilibrium $n=n_{h}$, then the expected procurement cost of a downstream firm without investing $s$ is

$$
c+\frac{3 \tau_{h}}{4 n_{h}}
$$

Vertical integration (together with investing $s$ by a downstream firm) will occur if and only if

$$
s+c<c+\frac{3 \tau_{h}}{4 n_{h}}-\left(2 n_{h} \int_{0}^{\frac{1}{2 n_{h}}} p_{i}\left(x_{i}\right) d x_{i}-c\right)=c+\frac{\tau_{h}}{4 n_{h}},
$$

or

$$
s<\frac{\tau_{h}}{4 n_{h}} \equiv s_{3}
$$

Thus, if in equilibrium $n^{*}=n_{h}$, a mass of $M G\left(s_{3}\right)$ buyers will vertically integrate with suppliers, or $M G\left(s_{3}\right)$ amount of $H^{\prime} s$ imports from $F$ will be intrafirm imports.

Summarizing the discussion above and using results from Proposition 1, we can characterize the equilibrium in the extended model as follows:

Proposition 2 In equilibrium of the extended model:

(1) If $k>\bar{k}$, the unique equilibrium is: $n^{*}=n_{h} ; M G\left(s_{3}\right)$ buyers vertically integrate with suppliers and invest only s, while the rest of buyers remain vertically separated and invest neither $s$ nor $k$.

(2) If $\frac{1}{4}\left(\frac{\tau_{h}}{n_{h}}-\frac{\tau_{l}}{n_{l}}\right)<k<\underline{k}$, the unique equilibrium is: $n^{*}=n_{l} ; m G\left(s_{1}\right)$ buyers vertically integrate with suppliers and invest only s, while the rest of buyers remain vertically separated and invest only $k$.

(3) If $\underline{k} \leq k \leq \bar{k}$, there are three equilibria: the two equilibria characterized above, and a 
third equilibrium (for $\underline{k}<k<\bar{k}$ ) where $n^{*}=n_{m} ; m G\left(s_{2}\right)$ buyers vertically integrate with suppliers and invest only $s$, while the rest of buyers remain vertically separated, $\alpha_{m}$ portion of them investing nothing and $1-\alpha_{m}$ portion of them investing only $k$.

Proposition 2 provides the basis for an interesting relationship between product variety and intrafirm trade in equilibrium. Notice that if $\underline{k} \leq k \leq \bar{k}$, we have $s_{1}>s_{2}>s_{3}$ since

$$
\begin{aligned}
& s_{1}=\frac{\tau_{l}}{4 n_{l}}+k=\frac{3 \tau_{l}-2 \tau_{l}}{4 n_{l}}+k>\frac{3 \tau_{l}-2 \tau_{m}}{4 n_{m}}+k=s_{2}, \\
& s_{2}=\frac{3 \tau_{h}-2 \tau_{m}}{4 n_{m}}>\frac{3 \tau_{h}-2 \tau_{h}}{4 n_{h}}=\frac{\tau_{h}}{4 n_{h}}=s_{3} .
\end{aligned}
$$

If $k<\underline{k}$ or $k>\bar{k}$, we have $s_{1}>s_{3}$ since

$$
s_{1}-s_{3}=\frac{\tau_{l}}{4 n_{l}}+k-\frac{\tau_{h}}{4 n_{h}}=k-\frac{1}{4}\left(\frac{\tau_{h}}{n_{h}}-\frac{\tau_{l}}{n_{l}}\right)>0 .
$$

We therefore have:

Corollary 2 Corresponding to the possible equilibrium numbers of product varieties $n_{l}<$ $n_{m}<n_{h}$, the amounts of vertical integration, or of intrafirm trade, are respectively $M G\left(s_{1}\right)>$ $M G\left(s_{2}\right)>M G\left(s_{3}\right)$. That is, more product varieties are associated with lower intrafirm trade.

This negative correlation between variety and intrafirm trade holds whether the parameter values of our model allows a unique equilibrium or multiple equilibria. Intuitively, the specific investment allows a buyer to improve its match quality with its favored supplier. When the number of suppliers is large, the buyer can expect its input needs to be matched relatively well by the supplier, and thus there is relatively low benefit to make the specific investment. On the other hand, when the number of suppliers is low, a buyer expects to incur more substantial adjustment cost to meet its input requirement, and thus there is high benefit from the specific investment. Consequently, in the latter case, the marginal buyer who can potentially benefit from making specific investment corresponds to a higher $s$, implying that there are more such buyers. However, while the flexible investment reduces the expected price for the buyer ex post, the specific investment raises this price due to 
the hold-up problem. Vertical integration is needed as a mechanism to solve the hold-up problem and realize the gains from specific investment. ${ }^{13}$

Our assumption that the downstream firms appropriate all the gains from vertical integration significantly simplifies the analysis. Under this assumption the upstream firms will receive the same payoff in this extended model as in the basic model (with or without vertical integration), so the incentive for entry in the upstream market is not changed; as a result, there is no change for the conditions on $k$ for the equilibrium number of suppliers. If the upstream firms' payoffs increase as a result of vertical integration, there will be additional upstream entry in equilibrium; this will complicate the analysis, but need not change the qualitative nature of our results.

Corollary 2 offers a testable prediction about product variety and intrafirm trade: import variety of the home country is negatively correlated with the amount of intrafirm trade (imports). We next test this predication empirically.

\section{EMPIRICAL SPECIFICATION AND DATA}

To test the hypotheses developed above, we make use of the data in Antràs (2003), who considered intrafirm imports from 28 countries to the United States, in 1992. He used Bureau of Economics Analysis (BEA) data to construct intrafirm imports to the U.S. in manufacturing industries. His hypothesis was that intrafirm imports should be higher in capital-intensive industries or from capital-abundant countries, which was supported by the regressions that he runs. In addition to the capital-intensity of industries, Antràs controls for factors such as human capital, corporate tax rates, and the openness of countries to trade and FDI.

Our key hypothesis is that a higher product variety of imports, such as coming from

\footnotetext{
${ }^{13}$ Note that if $H$ imports from several $F$ countries, then other factors that affect variety may need be controlled in order to make across-country comparisons. For instance, an $F$ country that is closer to $H$ or that is larger may export more variety to $H$ while at the same time also allow lower $s$ for the buyers in $H$, causing more vertical integration (intrafirm trade). Such considerations will be important for our empirical analysis later.
} 
Taiwan as compared to Korea in their sales to the U.S., are associated with lower intrafirm imports. The measure of import variety we shall use follows closely the approach of Feenstra (1994). He develops an index of product variety that is consistent with a CES aggregator function, even when that function is not symmetric across goods. This measure of product variety has been utilized recently by Borda and Weinstein (2004), for example, who consider the increasing variety of imports coming into the United States. Hummels and Klenow also use the CES measure of trade variety, and call it the "extensive margin" of a country's exports (as contrasted with the "intensive margin," which would be the quantity of exports rather then variety). Feenstra and Kee (2004) have recently studied how export variety from various countries to the U.S. impacts those country's aggregate productivity.

In order to test the relationship between product variety and intrafirm imports, however, it is important to control for other factors that influence import variety. Simple proximity of a country to the U.S., as well as sheer size of a country, will both lead to higher variety. We can control for these factors using two, closely related approaches. In the first approach, we estimate a gravity equation where the dependent variable is import variety to the U.S. from a partner country. The residuals from this gravity equation will then be used as an explanatory variable for intrafirm imports, in a regression that also includes the capitalabundance of countries and other explanatory variables used by Antràs. Under this first method we are simply adding a new variable - unexplained product variety - into the same regressions used by Antràs. The motivation for using unexplained product variety as a regressor, rather than total product variety, is the same as our motivation for using Taiwan and Korea as comparison: we want to control for other factors that would influence product variety and intrafirm trade.

In the second approach to estimation, we include control variables for country size, distance, etc. simultaneously with estimating the relationship between product variety and intrafirm imports. Because both of these variables are endogenous in our theory, in the second approach we use total product variety as the dependent variable, with the controls and intrafirm imports on the right. This approach has the benefit of estimating unexplained product variety and its relationship to intrafirm trade in a single equation. Since intrafirm 
trade is itself endogenous, we use instruments that come from the original Antràs regression, i.e. countries' capital and labor endowments.

In the next section we provide some details on the CES measure of import variety, which we measure for 104 countries selling to the U.S. in 1992 (the year of Antràs' data) and 1997. The later year is added since measures of intra-firm imports for the U.S. in 1997 are now available from the BEA (Zeile, 2003), but these data were not available to Antràs (2003). Thus, we are able to double the size of the dataset used for estimation. The BEA reports data on imports shipped by overseas affiliates to their U.S. parents, and imports shipped to U.S. affiliates by their foreign parent groups. Following Antràs, we initially focus on the sum of these two series for majority-owned affiliates. Unlike Antràs, however, we do no necessarily restrict ourselves to manufacturing industries, but consider intrafirm sales to manufacturing and wholesale industries.

\section{MEASUREMENT OF IMPORT VARIETY}

Let $P_{t}^{c}$ denote the value of a CES unit-cost function defined over the prices of all product varieties sold into the U.S. by country $c$ :

$$
P_{t}^{c} \equiv\left(\sum_{i \in I_{t}^{c}} b_{i}\left(p_{i t}^{c}\right)^{1-\sigma}\right)^{1 /(1-\sigma)}, b_{i}=a_{i}^{\sigma}>0, c=1, \ldots, C .
$$

and $p_{t}^{c}>0$ is the domestic price vector for each country, and we assume $\sigma>1$. Notice that the $b_{i}$ parameters allow for asymmetric demand for the products.

The function (2) cannot be evaluated without knowledge of the parameters $b_{i}$. But a standard result from index number theory is that the ratio of CES function can be evaluated, using data on price and quantities in the two periods or two countries. Feenstra (1994) shows how this result applies even when the number of goods is changing. In particular, the ratio of the CES aggregator functions over two countries $a$ and $b$, equals to the product of the Sato-Vartia price index of goods that are common, $I \equiv\left(I_{t}^{a} \cap I_{t}^{b}\right) \neq \varnothing$, multiplied by terms 
reflecting the cost share of "unique" goods:

$$
\frac{P_{t}^{a}}{P_{t}^{b}}=\prod_{i \in I}\left(\frac{p_{i t}^{a}}{p_{i t}^{b}}\right)^{w_{i}(I)}\left(\frac{\lambda_{t}^{a}(I)}{\lambda_{t}^{b}(I)}\right)^{1 /(1-\sigma)}, a, b=1, \ldots, C,
$$

where the weights $w_{i}(I)$ are constructed from the cost shares in the two countries:

$$
\begin{gathered}
w_{i}(I) \equiv\left(\frac{s_{i t}^{a}(I)-s_{i t}^{b}(I)}{\ln s_{i t}^{a}(I)-\ln s_{i t}^{b}(I)}\right) / \sum_{i \in I}\left(\frac{s_{i t}^{a}(I)-s_{i t}^{b}(I)}{\ln s_{i t}^{a}(I)-\ln s_{i t}^{b}(I)}\right) \\
s_{i t}^{c}(I) \equiv \frac{p_{i t}^{c} q_{i t}^{c}}{\sum_{i \in I} p_{i t}^{c} q_{i t}^{c}}, \text { for } c=a, b, \\
\lambda_{t}^{c}(I)=\frac{\sum_{i \in I} p_{i t}^{c} q_{i t}^{c}}{\sum_{i \in I_{t}^{c}} p_{i t}^{c} q_{i t}^{c}}=1-\frac{\sum_{i \in I_{t}^{c}, i \notin I} p_{i t}^{c} q_{i t}^{c}}{\sum_{i \in I_{t}^{c}} p_{i t}^{c} q_{i t}^{c}}, \text { for } c=a, b .
\end{gathered}
$$

Notice that the cost shares in (5), for each country, are measured relative to the common set of goods I. Then the weights in (4) are the logarithmic mean of the shares $s_{i t}^{a}(I)$ and $s_{i t}^{b}(I)$, and sum to unity over the set of goods $i \in I$.

The first term on the right of (3) is the Sato (1976)-Vartia (1976) price index, which is simply a weighted average of the price ratios, using the values $w_{i}(I)$ as weights. What is new about equation (3) is the second term on the right, which reflects changes in product variety. If country $c$ in period $t$ has new, unique products (not in the common set $I$ ), we will have $\lambda_{t}^{c}<1$. From (3), when $\sigma>1$ then $\lambda_{t}^{c}<1$ will lower the price index of imports, $P_{t}^{a} / P_{t}^{b}$. In other words, the introduction of new import varieties will act in the same way as an reduction in prices from that country, providing a welfare gain to consumers.

In practice, we will measure the ratio $\lambda_{t}^{a} / \lambda_{t}^{b}$ using the 10-digit Harmonized System (HS) classification of U.S. imports. To measure the ratio $\lambda_{t}^{a} / \lambda_{t}^{b}$, we need to decide on a consistent "comparison country." For this purpose, we shall use the worldwide imports from all countries to the U.S. as the comparison. Denote this comparison country by ${ }^{*}$, so that the set $I_{t}^{*}=\cup_{c=1}^{C} I_{t}^{c}$ is the complete set of varieties imported by the United States in year $t$. Then comparing country $c$ to country $*$ in year $t$, it is immediate that the common set of goods exported is $I_{t}^{c} \cap I_{t}^{*}=I_{t}^{c}$, or simply the set of exported by country $c$. Therefore, from (6) we have that $\lambda_{t}^{c}=1$, and that:

$$
\lambda_{t}^{*}\left(I_{t}^{c}\right)=\frac{\sum_{i \in I_{t}^{c}} p_{i t}^{*} q_{i t}^{*}}{\sum_{i \in I_{t}^{*}} p_{i t}^{*} q_{i t}^{*}}=1-\frac{\sum_{i \in I_{t}^{*}, i \notin I_{t}^{c}} p_{i t}^{*} q_{i t}^{*}}{\sum_{i \in I_{t}^{*}} p_{i t}^{*} q_{i t}^{*}} .
$$


Noting from (3) that product variety in country $c$ relative to the comparison is measured as $\lambda_{t}^{c} / \lambda_{t}^{*}$, we will instead invert it and obtain a direct measure of import variety from country $c$ relative to the world, as $\lambda_{t}^{*} / \lambda_{t}^{c}=\lambda_{t}^{*}$. The interpretation of $\lambda_{t}^{*}$ in (7) is that it is the share of worldwide imports into the U.S. from products that are sold by country c. Equivalently, it is one minus the share of worldwide imports from products that are not sold by country $c$. Note that this measure depends on the set of products sold by country $c, I_{t}^{c}$, but not on its value of imports to the U.S., except insofar as they affect the value of worldwide imports. We use (7) as our measure of import variety from each country $c$ to the United States, and it is the same as what Hummels and Klenow (2002) call an "extensive margin.".

\section{EMPIRICAL RESULTS}

We first estimate a gravity equation for 104 countries selling to the United States, in 1992 and 1997, with the results shown in column (1) Table 1. Explanatory variables included in the gravity equation are GDP per capita as well as population in each partner country, along with distance to the U.S. (all in natural logs), and these are all significant at the 1\% level. We also add several indicator variables: for a common border with the U.S.; for OECD members; OPEC members; and having English as the primary language ${ }^{14}$ The OPEC and English language indicators are both insignificant, but the other variables are highly significant. ${ }^{15}$

We construct the residuals from column (1) and label them as "variety residual". This variable will be used as an explanatory variables in our first empirical approach, which builds upon the country regression used by Antràs (2003, Table V), and is described in Tables $2-4$. The remaining regressions in Table 1 will be discussed under our second empirical approach.

\footnotetext{
${ }^{14}$ These indicator variables are used by Feenstra, Markusen and Rose (2001), from whom we obtain the distance measures.

${ }^{15}$ The indicator variable for common border is also significant, but has an unexpected negative sign. This may be offsetting the larger positive coefficient on the OECD indicator, which might be over-predicting the impact of OECD membership for Canada on export variety sold to the U.S.
} 


\section{First Empirical Approach}

Focusing for a moment on the 28 countries considered by Antràs (2003) for 1992, in Figures 1 and 2 we graph import variety and the variety residual, respectively, against the intrafirm imports from each country. ${ }^{16}$ Antràs uses the intrafirm imports within manufacturing industries, so that is what we show on the horizontal axis in Figures 1 and 2. The vertical axis of Figure 1 is the import variety from each country in their sales to the U.S. As suggested by Figure 1, import variety is positively correlated with intrafirm imports, as is confirmed if it is included as an additional variable in the country regressions of Antràs (2003). The countries with the highest product variety of sales to the U.S. include Canada, Mexico and the U.K., and these countries also have high intrafirm imports. But we believe that the positive raw correlation between product variety and intrafirm trade is determined by third factors, such as proximity for Canada and Mexico and common language with the U.K., that co-determine product variety of trade with the U.S. and foreign direct investment.

In Figure 2 the vertical axis measured the variety residual, after controlling for the variables in the gravity equation. The variety residual appears to be negatively correlated with intrafirm imports, as is confirmed if the variety residual is included in the country regressions of Antràs (2003). We report versions of these regressions below that expand on the number of countries and years used in the estimation, and also modify the measure of intrafirm imports that is used. Antràs (2003) focuses on intrafirm imports within manufacturing industries of the U.S., in 1992, since manufacturing most closely matches his theory. But our theory is well suited to include sales to wholesale industries, too. So we use intrafirm imports to the U.S. in both manufacturing and wholesale industries, measured as a percentage of total U.S. imports from that foreign country, as reported by Zeile (1997, 2003) for 1992 and $1997 .^{17}$

\footnotetext{
${ }^{16}$ The data used in these Figures is reported in the Appendix.

${ }^{17}$ It turns out that the results using just intrafirm imports in manufacturing, or intrafirm imports in manufacturing plus wholesale industries, are quite similar, which is why we do not make the distinction. By including both sectors we can use the reported data in Zeile (1997, 2003), which is available for a broader sample of countries than used by Antràs. Regressions similar to Table 2, but using just manufacturing and
} 
In Table 2, we use intrafirm imports as the dependent variable, summing over sales by foreign affiliates to their U.S. parents and sales by foreign parents to their U.S. affiliates. The explanatory variables used are the same as in Antràs (2003): regression (1) uses the capital-labor ratio of each country; regression (2) adds the labor stock; regression (3) adds the human capital-labor ratio; regression (4) adds the corporate tax rate, and the following regressions add indexes of openness to FDI, to trade, and overall economic freedom. It can be seen that the variety residual is not significant initially, but become highly significant as more controls are added. It is negatively correlated with intrafirm trade, as suggested by our theory. The capital-labor ratio, which is the key variable suggested by Antràs' model, retains its positive and significant sign as the number of observations are expanded from his sample.

In Table 3 we use U.S. parents imports from their foreign affiliates as the dependent variable, and in Table 4 we use U.S. affiliates imports from their foreign parents. In Table 3 , the variety residual is negative and significant in all specifications. But the capital-labor ratio loses its significance entirely. So when U.S. parents are importing from their affiliates abroad, the theory we have presented here appears to hold quite well, whereas the positive relationship between capital-intensity and intrafirm trade, as posited by Antràs, does not hold. Antràs argues that having capital-intensive production exacerbates the "hold up" problem between firms, making vertical integration more likely. The capital-labor ratio included in these regressions applies to the partner country, but when only the affiliate is located there, it may be specialized in a narrow range of activities as compared to the parent and therefore not have the same capital-intensity of production. This may explain why Antràs hypothesis is not confirmed. The theory presented in this paper is based on investment by the buyer, so it is natural to expect this theory to hold when the buyer is the parent firm, and therefore dominant in the relationship.

When we consider U.S. affiliates imports from their foreign parents in Table 4, then there is a very strong positive relationship with capital-intensity. In this case, the high capital-labor ratio of the foreign country applies to location of the foreign parent firm, just the 28 countries used by Antràs for 1992, are available on request. 
which appears to be a better way to measure the relevant capital-intensity in production, thereby confirming Antràs' theory. The negative relationship between the variety residual and intrafirm trade also holds, supporting our own hypothesis, but is only significant when some controls are added.

\section{Second Empirical Approach}

So far, we have followed Antràs in using intrafirm imports as the dependent variable in our regressions. Both that variable and product variety are endogenous in our theory, so we can equally well use product variety as the dependent variable. Such an approach has a major advantage in that we can then include the control variables in the gravity regression simultaneously with using intrafirm trade as an explanatory variable. Furthermore, we can take account of the endogeneity of intrafirm trade by using instruments suggested by Antràs, i.e. the factor endowments of countries. This is the approach we pursue now, with results reported in the remaining columns of Table 1.

The gravity equation in column (1) of Table (1) is estimated over a wide cross-section of countries, and we would like to retain the same broad coverage when including intrafirm trade as a regressor. The difficulty, however, is that many countries do not report any intrafirm trade with the U.S. in the BEA surveys, and so are not included in Zeile (1997, 2003). We presume that these countries have minimal intrafirm trade, and then construct the ratio of intrafirm trade to total country imports as:

$$
\text { Intrafirm import ratio }=\left\{\begin{array}{l}
\ln (\text { intrafirm imports/country imports) if reported by BEA } \\
\delta_{t} \text { if intrafirm imports are not reported by BEA in year } t
\end{array}\right.
$$

Under this formulation, $\delta_{t}$ denotes the natural log of the (intrafirm imports/country imports) ratio for countries not reporting to the BEA.

In order to include $\delta_{t}$ in our estimation, it is convenient to break up the intrafirm 
import ratio into two distinct variables, as follows:

$$
\text { Intrafirm import ratio }=\left\{\begin{array}{c}
\ln (\text { intrafirm imports } / \text { country imports }) \text { if reported by BEA } \\
0 \text { if intrafirm imports are not reported by BEA in year } t
\end{array}\right.
$$

and,

Missing intrafirm indicator $=\left\{\begin{array}{c}0 \text { if intrafirm imports are reported by BEA in year } t \\ 1 \text { if intrafirm imports are not reported by BEA in year } t\end{array}\right.$

Now the parameter $\delta_{t}$ becomes the estimated coefficient on the missing intrafirm indicator variable.

In column (2) of Table 1, we report the gravity equation using the log of import variety as the dependent variable, and including the intrafirm import ratio and missing intrafirm indicator as defined above. The coefficient of intrafirm imports is negative, but very small in magnitude and insignificantly different from zero. The coefficient of the missing intrafirm indicator is also negative, and highly significant. The negative estimate of $\delta_{t}$ should be interpreted as an estimate of (intrafirm imports/total country imports) for the missing countries that is less than one percent, so its natural log is negative. ${ }^{18}$

In column (3) of Table 1, we correct for the endogeneity of the intrafirm imports by using instruments for this variable: the capital-labor ratio, labor endowment, and human capital-labor ratio for each country. These are the same variables used by Antràs (2003), as taken from Hall and Jones (1999). When constructing the first-stage value of the intrafirm import ratio, we use instruments only for those observations that have positive intrafirm imports. That is, we construct the variable:

Predicted Intrafirm import ratio $=\left\{\begin{array}{c}\text { Predicted value of } \ln (\text { intrafirm imports/country imports }) \\ 0 \text { if intrafirm imports are not reported by BEA in year } t\end{array}\right.$ The predicted value of $\ln$ (intrafirm imports/country imports) is obtained from a regression like that shown in column (3) of Table 2 , but omitting the variety residual variable. That

\footnotetext{
${ }^{18}$ Notice that we measure (intrafirm imports/total country imports) as a percentage, so Canada appears as about 45 , for example.
} 
regression has 88 observations, reflecting intrafirm trade for roughly 44 countries reported by the BEA in 1992 and 1997 . We then add the zero value for the other $(207-44)=163$ observations included in the gravity equation.

Using the predicted intrafirm import ratio, along with the missing intrafirm indicator, the results are shown in column (3) of Table 1. The intrafirm import ratio is still negative, and is now significantly different from zero. This confirms our hypothesis that intrafirm trade is negatively correlated with product variety, after controlling for other factors. Notice,

however, that the negative coefficient on intrafirm trade is sensitive to the fact that we have also included the missing intrafirm indicator variable in the gravity equation: if that indicator variable is dropped, then the coefficient of the intrafirm import ratio switches from negative to positive.

In the remaining two regressions reported in Table 1, we consider narrower measures of the intrafirm import ratio. In column (4), we use only U.S. parent's intrafirm imports from their foreign affiliates, measured relative to country imports, to construct the intrafirm import ratio. In column (5) we use only U.S. affiliate's intrafirm imports from their foreign parents, measured relative to country imports, to construct the intrafirm import ratio. These two specifications are the same as the dependent variables that we used in Tables 3 and 4 . The intrafirm import ratio is negative and significant in both cases, confirming our hypothesis.

\section{CONCLUDING REMARKS}

This paper has studied a simple model of buyer investment and its effect on the variety and vertical structure of international trade. The model distinguishes between two types of buyer investment: "flexible" and "specific". An analysis of these two types of investment, and of their interactions with the entry and pricing incentives of suppliers, yields two major insights. First, the tension between upstream variety and downstream flexibility can give rise to multiple equilibria in the variety of products traded. While our empirical analysis does not explicitly address the issue of multiple equilibria, this theoretical result is consistent with the observation that Taiwan and South Korea, despite the similarities in their 
underlying economies, have very different structures of export varieties to the U.S. Second, since the potential gains from specific investment is higher with less product variety, and since vertical integration can serve as a mechanism to overcome the hold-up problem under specific investment, less product variety is associated with more intrafirm trade. This implication of our theory is supported by the result from our formal empirical analysis.

The negative correlation between variety and intrafirm trade is an interesting finding of this paper. In view of Figure 1, this is a rather surprising result, since the two variables appear on the surface to be positively correlated in a raw data. Our empirical analysis is able to uncover this relationship, suggested from our theory, by controlling for other factors that could influence these two variables. This is a case that clearly demonstrates the power of combining theoretical analysis with empirical work, where the empirical work is pursued in a direction that is otherwise overlooked.

There are several interesting directions for future research. One possibility is to further expand our model to allow a consideration of the internal organization of the firms involved in intrafirm trade, such as how the control rights are allocated within a firm. Another possibility for future work is to expand our model to allow the downstream firms the additional possibilities of producing or purchasing the intermediate goods internally or domestically. It would also be interesting to consider the effects of downstream competition on the vertical organization of international trade. These extensions could potentially shed new light on the mode of international acquisitions or foreign direct investment, as well as on the motives for and effects of intrafirm trade and international outsourcing. 
Appendix: Country data, 1992

\begin{tabular}{l|cccc}
\hline \multicolumn{1}{c|}{ Country } & $\begin{array}{c}\text { Intrafirm } \\
\text { Share }\end{array}$ & $\begin{array}{c}\text { Capital } \\
\text { /Labor }\end{array}$ & $\begin{array}{c}\text { Import } \\
\text { Variety }\end{array}$ & $\begin{array}{c}\text { Variety } \\
\text { Residual }\end{array}$ \\
\hline \hline Switzerland & 64.1 & 107.9 & 60.7 & 1.02 \\
Singapore & 55.4 & 56.2 & 55.1 & 2.62 \\
Ireland & 53.7 & 55.7 & 39.7 & 0.49 \\
Canada & 45.1 & 82.4 & 93.9 & 0.92 \\
Netherlands & 42.2 & 79.1 & 58.3 & 0.85 \\
Mexico & 41.7 & 28.4 & 81.1 & 1.08 \\
Panama & 35.8 & 19.8 & 19.6 & 0.95 \\
U.K. & 33.2 & 50.4 & 88.9 & 0.53 \\
Germany & 31.9 & 89.4 & 81.8 & 0.78 \\
Malaysia & 30.1 & 23.5 & 48.8 & 2.70 \\
Belgium & 27.3 & 76.5 & 58.0 & 1.58 \\
Brazil & 25.9 & 21.2 & 60.9 & 0.42 \\
France & 21.6 & 84.9 & 82.2 & 1.06 \\
Sweden & 16.8 & 72.8 & 57.1 & 1.18 \\
Spain & 15.5 & 61.6 & 53.7 & 1.38 \\
Australia & 15.5 & 88.1 & 62.7 & 0.77 \\
Japan & 14.2 & 64.2 & 85.8 & 1.75 \\
Israel & 12.4 & 51.8 & 44.8 & 2.69 \\
Hong Kong & 11.2 & 29.1 & 54.8 & 2.68 \\
Philippines & 8.4 & 8.0 & 44.2 & 2.19 \\
Italy & 8.1 & 82.3 & 79.8 & 2.90 \\
Argentina & 5.1 & 33.2 & 35.9 & 1.16 \\
Colombia & 4.6 & 15.4 & 36.4 & 3.34 \\
Taiwan & 4.6 & 26.2 & 59.3 & 4.12 \\
Venezuela & 1.4 & 42.7 & 37.2 & 1.94 \\
Chile & 1.3 & 22.5 & 20.8 & 2.47 \\
Indonesia & 1.3 & 8.1 & 43.3 & 4.36 \\
Egypt & 0.1 & 3.4 & 21.4 & 0.98 \\
Average & 22.4 & 49.5 & 55.9 & 1.75 \\
\hline & & & & \\
\hline
\end{tabular}

\section{Notes:}

Intrafirm trade is the sum of imports shipped by overseas affiliates to their U.S. parents, and import shipped to U.S. affiliates by their foreign parent groups, measured as a percentage of total U.S. imports from that foreign country, as reported by Antràs (2003).

Capital/labor endowment of each country is for 1988, where the capital stock is measured in \$thousands per worker, as reported by Hall and Jones (1999). The import variety measure is constructed as in (6), and the variety residual is the residual from the gravity equation in columns (1) of Table 1. 


\section{REFERENCES}

[1] Antràs, Pol. 2003, "Firms, Contracts, and Trade Structure," Quarterly Journal of Economics, 118, 1375-1418.

[2] Antràs, Pol and Elhanan Helpman, 2004, "Global Sourcing," Journal of Political Economy, $112(3), 552-580$.

[3] Chen, Yongmin, "Marketing Innovation," Journal of Economics and Management Strategy, forthcoming.

[4] Feenstra, Robert C., 1994, "New Product Varieties and the Measurement of International Prices," American Economic Review, 84(1), March, 157-177.

[5] Feenstra, Robert C. and Gary G. Hamilton, 2004, Emergent Economics, Divergent Paths: Economic Organization and International Trade in South Korea and Taiwan, Cambridge University Press, forthcoming.

[6] Feenstra, Robert C. and Hiau Looi Kee, 2004, "Export Variety and Country Productivity," NBER Working Paper no. 10830.

[7] Feenstra, Robert C., James R. Markusen and Andrew K. Rose, 2001, "Using the Gravity Equation to Differentiate Among Alternative Theories of Trade," Canadian Journal of Economics, 34(2), May, 430-447.

[8] Feenstra, Robert C., Tzu-Han Yang, and Gary G. Hamilton, 1999, "Business Groups and Product Variety in Trade: Evidence from South Korea, Taiwan and Japan," Journal of International Economics, 48, June, 71-100.

[9] Gereffi, Gary and Pan Mei-lin. 1994. "The Globalization of Taiwan's Garment Industry." Pp. 126-146 in Global Production: The Apparel Industry in the Pacific Rim, Edna Bonacich, Lucie Cheng, Norma Chinchilla, Nora Hamilton, and Paul Ong (eds.). Philadelphia: Temple University Press. 
[10] Gereffi, Gary, 1994, "The International Economy and Economic Development." Pp. 206-233 in The Handbook of Economic Sociology, edited by Neil Smelser and Richard Swedberg. Princeton: Princeton University Press.

[11] Grossman, Sanford J. and Oliver D. Hart, 1986, "The Costs and Benefits of Ownership: A Theory of Vertical and Lateral Integration," Journal of Political Economy, 94, 691-785.

[12] Hall, Robert E. and Charles I Jones, 1999, "Why Do Some Countries Produce So Much More Output per Workers than Others?" quarterly Journal of Economics, 114, 83-116.

[13] Hummels, David L. and Klenow, Peter J., 2002, “The Variety and Quality of a Nation's Trade,” NBER Working Paper No. 8712, American Economic Review, forthcoming.

[14] Joskow, Paul L., "Contractual Duration and Relationship-Specific Investment: Empirical Evidence from Coal Markets," American Economic Review, 77, 168-185.

[15] McLaren, John, 2000, "'Globalization' and Vertical Structure," American Economic Review, 90, 1239-1254.

[16] Sato, Kazuo (1976) "The Ideal Log-Change Index Number," Review of Economics and Statistics 58, May, 223-228.

[17] Vartia, Y.O. (1976) "Ideal Log-Change Index Numbers", Scandinavian Journal of Statistics $3,121-126$.

[18] Volker Nocke and Stephen Yeaple, 2004, "An Assignment Theory of Foreign Direct Investment," NBER Working paper no 11003.

[19] Zeile, William J., 1997, "U.S. Intrafirm Trade in Goods," Survey of Current Business, February, 23-38.

[20] Zeile, William J., 2003, "Trade in Goods Within Multinational Companies: Survey-Based Data and Findings for the United States of America," Bureau of Economics Analysis, mimeo. 
Table 1: Gravity equation for U.S. imports, by partner countries, 1992 and 1997

\begin{tabular}{|c|c|c|c|c|c|}
\hline \multicolumn{6}{|c|}{ Dependent variable: Product Variety } \\
\hline & (1) & $(2)$ & (3) & (4) & (5) \\
\hline U.S. GDP per capita & $\begin{array}{l}1.456 \\
(1.85)\end{array}$ & $\begin{array}{c}3.053^{* *} \\
(4.44)\end{array}$ & $\begin{array}{c}3.193^{* *} \\
(4.69)\end{array}$ & $\begin{array}{l}3.206^{* *} \\
(4.85)\end{array}$ & $\begin{array}{l}2.936^{* *} \\
(4.34)\end{array}$ \\
\hline GDP per capita & $\begin{array}{l}0.185^{\star *} \\
(10.61)\end{array}$ & $\begin{array}{c}0.134^{* *} \\
(8.25)\end{array}$ & $\begin{array}{c}0.142^{* *} \\
(8.52)\end{array}$ & $\begin{array}{l}0.146^{* *} \\
(8.32)\end{array}$ & $\begin{array}{l}0.146^{* *} \\
(9.48)\end{array}$ \\
\hline Population & $\begin{array}{c}0.270^{* *} \\
(8.66)\end{array}$ & $\begin{array}{c}0.153^{* *} \\
(5.45)\end{array}$ & $\begin{array}{c}0.137^{* *} \\
(4.82)\end{array}$ & $\begin{array}{l}0.146^{\star *} \\
(5.67)\end{array}$ & $\begin{array}{l}0.122^{\star *} \\
(4.16)\end{array}$ \\
\hline Distance to U.S. & $\begin{array}{c}-0.318^{* *} \\
(2.72)\end{array}$ & $\begin{array}{l}-0.189 \\
(1.87)\end{array}$ & $\begin{array}{l}-0.187 \\
(1.82)\end{array}$ & $\begin{array}{l}-0.230^{*} \\
(2.32)\end{array}$ & $\begin{array}{l}-0.217^{*} \\
(2.13)\end{array}$ \\
\hline Common border & $\begin{array}{c}-0.593^{* *} \\
(2.81)\end{array}$ & $\begin{array}{l}-0.366 \\
(1.78)\end{array}$ & $\begin{array}{l}-0.255 \\
(1.22)\end{array}$ & $\begin{array}{l}-0.107 \\
(0.46)\end{array}$ & $\begin{array}{l}-0.674^{\star *} \\
(3.38)\end{array}$ \\
\hline OECD member & $\begin{array}{c}0.885^{\star *} \\
(8.28)\end{array}$ & $\begin{array}{c}0.647^{\star *} \\
(6.13)\end{array}$ & $\begin{array}{c}0.769^{* *} \\
(7.45)\end{array}$ & $\begin{array}{l}0.640^{* *} \\
(6.79)\end{array}$ & $\begin{array}{l}0.820^{* *} \\
(7.49)\end{array}$ \\
\hline OPEC member & $\begin{array}{l}0.012 \\
(0.03)\end{array}$ & $\begin{array}{l}-0.136 \\
(0.45)\end{array}$ & $\begin{array}{r}-0.084 \\
(0.27)\end{array}$ & $\begin{array}{l}-0.005 \\
(0.02)\end{array}$ & $\begin{array}{l}-0.015 \\
(0.05)\end{array}$ \\
\hline English Language & $\begin{array}{l}0.171 \\
(1.45)\end{array}$ & $\begin{array}{l}0.122 \\
(1.19)\end{array}$ & $\begin{array}{l}0.142 \\
(1.41)\end{array}$ & $\begin{array}{l}0.155 \\
(1.54)\end{array}$ & $\begin{array}{l}0.056 \\
(0.57)\end{array}$ \\
\hline Intrafirm import ratio & & $\begin{array}{l}-0.061 \\
(0.86)\end{array}$ & $\begin{array}{c}-0.328^{*} \\
(2.54)\end{array}$ & $\begin{array}{l}-0.252^{*} \\
(2.35)\end{array}$ & $\begin{array}{l}-0.357^{* *} \\
(4.16)\end{array}$ \\
\hline $\begin{array}{l}\text { Missing intrafirm } \\
\text { indicator }\end{array}$ & & $\begin{array}{c}-1.147^{* *} \\
(4.87)\end{array}$ & $\begin{array}{c}-1.909^{* *} \\
(4.77) \\
\end{array}$ & $\begin{array}{l}-1.448^{* *} \\
(6.44)\end{array}$ & $\begin{array}{l}-1.754^{\star *} \\
(8.05)\end{array}$ \\
\hline Observations & 207 & 207 & 207 & 207 & 207 \\
\hline R-squared & 0.61 & 0.71 & 0.72 & 0.73 & 0.72 \\
\hline
\end{tabular}

Robust standard errors in parentheses, ${ }^{*}$ significant at $5 \% ;{ }^{* *}$ significant at $1 \%$

\section{Notes:}

All variables except indicators are measured in natural logs. The residuals from column (1) are used as variety residual in Tables 2-4. Columns (1) and (2) are estimated with OLS, while columns (3) - (5) uses instruments (K/L, L and H/L) for positive values of intrafirm imports, as explained in the text. The intrafirm indicator variable equals one if intrafirm imports are not reported by BEA, and zero otherwise. In column (4), we use only U.S. parent's intrafirm imports from their foreign affiliates, measured relative to country imports, to construct the intrafirm import ratio. In column (5) we use only U.S. affiliate's intrafirm imports from their foreign parents, measured relative to country imports, to construct the intrafirm import ratio. These two specifications are the same as the dependent variables that are used in Tables 3 and 4. 
Table 2: Regressions of Intrafirm Trade, by partner countries, 1992 and 1997

\begin{tabular}{|c|c|c|c|c|c|c|}
\hline \multicolumn{7}{|c|}{$\begin{array}{c}\text { Dependent variable: Intrafirm imports relative to country imports, } \\
\text { U.S. affiliate and U.S. parent imports }\end{array}$} \\
\hline & (1) & (2) & (3) & (4) & (5) & (6) \\
\hline \multirow[t]{2}{*}{$\operatorname{Ln}(K / L)$} & $0.489^{\star *}$ & $0.490^{* *}$ & $0.434^{* *}$ & $0.388^{\star *}$ & $0.269^{\star *}$ & $0.579^{\star *}$ \\
\hline & $(0.072)$ & $(0.069)$ & $(0.079)$ & $(0.095)$ & $(0.094)$ & $(0.142)$ \\
\hline \multirow[t]{2}{*}{$\operatorname{Ln}(L)$} & & 0.001 & -0.005 & -0.022 & -0.027 & 0.048 \\
\hline & & $(0.047)$ & $(0.049)$ & $(0.066)$ & $(0.063)$ & $(0.081)$ \\
\hline \multirow[t]{2}{*}{$\operatorname{Ln}(H / L)$} & & & 0.315 & 0.576 & 0.312 & 0.763 \\
\hline & & & $(0.301)$ & $(0.472)$ & $(0.515)$ & $(0.532)$ \\
\hline \multirow[t]{2}{*}{ Corporate tax } & & & & $-3.206^{\star *}$ & $-2.817^{*}$ & $-3.397^{*}$ \\
\hline & & & & $(1.146)$ & $(1.131)$ & $(1.325)$ \\
\hline \multirow[t]{2}{*}{ Open FDI } & & & & & & -0.143 \\
\hline & & & & & & $(0.075)$ \\
\hline \multirow[t]{2}{*}{ Open Trade } & & & & & & 0.109 \\
\hline & & & & & & $(0.097)$ \\
\hline \multirow[t]{2}{*}{ Econ freedom } & & & & & $0.204^{\star *}$ & \\
\hline & & & & & $(0.069)$ & \\
\hline \multirow[t]{2}{*}{ Variety Residual } & -0.178 & -0.178 & -0.215 & $-0.509^{* *}$ & $-0.473^{\star *}$ & $-0.477^{* *}$ \\
\hline & $(0.122)$ & $(0.122)$ & $(0.126)$ & $(0.138)$ & $(0.139)$ & $(0.154)$ \\
\hline \multirow[t]{2}{*}{ Constant } & $-1.872^{*}$ & -1.900 & -1.490 & 0.221 & 0.352 & -2.675 \\
\hline & $(0.768)$ & $(1.072)$ & $(1.192)$ & $(1.893)$ & $(1.848)$ & $(2.622)$ \\
\hline Observations & 88 & 88 & 88 & 70 & 70 & 64 \\
\hline R-squared & 0.41 & 0.41 & 0.43 & 0.52 & 0.57 & 0.61 \\
\hline
\end{tabular}

Robust standard errors in parentheses, * significant at $5 \%$; ${ }^{* *}$ significant at $1 \%$

\section{Notes:}

The dependent variable differs from that used by Antràs (2003), since it includes sales of foreign companies to their manufacturing and to their wholesale affiliates in the U.S. Except for Variety Residual, which is the residual from the gravity equation in column (1) of Table 1, all the other explanatory variables are the same as in Antràs (2003). 
Table 3: Regressions of Intrafirm Trade, by partner countries, 1992 and 1997

\begin{tabular}{|c|c|c|c|c|c|c|}
\hline \multicolumn{7}{|c|}{$\begin{array}{l}\text { Dependent variable: U.S. parent's intrafirm imports from their } \\
\text { foreign affiliates, relative to country imports }\end{array}$} \\
\hline & (1) & (2) & (3) & (4) & (5) & (6) \\
\hline $\operatorname{Ln}(K / L)$ & $\begin{array}{c}0.295 \\
(0.154)\end{array}$ & $\begin{array}{c}0.313 \\
(0.165)\end{array}$ & $\begin{array}{c}0.128 \\
(0.150)\end{array}$ & $\begin{array}{l}-0.101 \\
(0.123)\end{array}$ & $\begin{array}{c}-0.263 \\
(0.149)\end{array}$ & $\begin{array}{c}-0.113 \\
(0.218)\end{array}$ \\
\hline $\operatorname{Ln}(L)$ & & $\begin{array}{c}0.032 \\
(0.090)\end{array}$ & $\begin{array}{c}0.015 \\
(0.089)\end{array}$ & $\begin{array}{l}-0.197 \\
(0.100)\end{array}$ & $\begin{array}{l}-0.203^{*} \\
(0.099)\end{array}$ & $\begin{array}{c}-0.096 \\
(0.156)\end{array}$ \\
\hline $\operatorname{Ln}(H / L)$ & & & $\begin{array}{c}1.018 \\
(0.515)\end{array}$ & $\begin{array}{c}0.177 \\
(0.507)\end{array}$ & $\begin{array}{l}-0.182 \\
(0.593)\end{array}$ & $\begin{array}{c}0.374 \\
(0.714)\end{array}$ \\
\hline Corporate tax & & & & $\begin{array}{l}-0.593 \\
(1.982)\end{array}$ & $\begin{array}{l}-0.064 \\
(2.049)\end{array}$ & $\begin{array}{l}-1.202 \\
(2.066)\end{array}$ \\
\hline Open FDI & & & & & & $\begin{array}{l}-0.088 \\
(0.147)\end{array}$ \\
\hline Open Trade & & & & & & $\begin{array}{c}0.289 \\
(0.152)\end{array}$ \\
\hline Econ freedom & & & & & $\begin{array}{l}0.278^{\star} \\
(0.124)\end{array}$ & \\
\hline Variety Residual & $\begin{array}{l}-0.493^{*} \\
(0.231)\end{array}$ & $\begin{array}{l}-0.493^{*} \\
(0.232)\end{array}$ & $\begin{array}{c}-0.604^{\star \star} \\
(0.215)\end{array}$ & $\begin{array}{l}-0.551^{*} \\
(0.217)\end{array}$ & $\begin{array}{l}-0.502^{\star} \\
(0.226)\end{array}$ & $\begin{array}{c}-0.597^{\star} \\
(0.283)\end{array}$ \\
\hline Constant & $\begin{array}{c}-0.850 \\
(1.648) \\
\end{array}$ & $\begin{array}{l}-1.531 \\
(2.613) \\
\end{array}$ & $\begin{array}{l}-0.222 \\
(2.503) \\
\end{array}$ & $\begin{array}{l}6.638^{\star} \\
(2.674)\end{array}$ & $\begin{array}{l}6.817^{\star *} \\
(2.524)\end{array}$ & $\begin{array}{c}3.947 \\
(4.810) \\
\end{array}$ \\
\hline Observations & 87 & 87 & 87 & 70 & 70 & 64 \\
\hline R-squared & 0.12 & 0.13 & 0.18 & 0.17 & 0.24 & 0.26 \\
\hline
\end{tabular}

Robust standard errors in parentheses, * significant at $5 \%$; ${ }^{* *}$ significant at $1 \%$

\section{Notes:}

The dependent variable differs from Table 2 in that it only includes imports by U.S. parents from their foreign affiliates. Except for Variety Residual, which is the residual from the gravity equation in column (1) of Table 1, all the other explanatory variables are the same as in Antràs (2003). 
Table 4: Regressions of Intrafirm Trade, by partner countries, 1992 and 1997

\section{Dependent variable: U.S. affiliate's intrafirm imports from their foreign parents, relative to country imports}

\begin{tabular}{|c|c|c|c|c|c|c|}
\hline & (1) & (2) & (3) & (4) & (5) & (6) \\
\hline \multirow[t]{2}{*}{$\operatorname{Ln}(K / L)$} & $0.738^{\star *}$ & $0.711^{* *}$ & $0.673^{* *}$ & $0.744^{* *}$ & $0.740^{* \star}$ & $0.990^{* *}$ \\
\hline & $(0.104)$ & $(0.111)$ & $(0.106)$ & $(0.142)$ & $(0.130)$ & $(0.127)$ \\
\hline \multirow[t]{2}{*}{$\operatorname{Ln}(\mathrm{L})$} & & -0.039 & -0.044 & 0.061 & 0.061 & 0.126 \\
\hline & & $(0.060)$ & $(0.062)$ & $(0.079)$ & $(0.079)$ & $(0.084)$ \\
\hline \multirow[t]{2}{*}{$\operatorname{Ln}(H / L)$} & & & 0.210 & $1.013^{*}$ & $1.004^{*}$ & $1.268^{* *}$ \\
\hline & & & $(0.346)$ & $(0.465)$ & $(0.452)$ & $(0.311)$ \\
\hline \multirow[t]{2}{*}{ Corporate tax } & & & & $-5.421^{* *}$ & $-5.410^{* *}$ & $-5.495^{\star \star}$ \\
\hline & & & & $(1.097)$ & $(1.096)$ & (1.135) \\
\hline \multirow[t]{2}{*}{ Open FDI } & & & & & & -0.034 \\
\hline & & & & & & $(0.073)$ \\
\hline \multirow[t]{2}{*}{ Open Trade } & & & & & & -0.045 \\
\hline & & & & & & $(0.095)$ \\
\hline \multirow[t]{2}{*}{ Econ freedom } & & & & & 0.007 & \\
\hline & & & & & $(0.073)$ & \\
\hline \multirow[t]{2}{*}{ Variety Residual } & -0.079 & -0.084 & -0.109 & $-0.476^{\star *}$ & $-0.475^{\star *}$ & $-0.323^{*}$ \\
\hline & $(0.124)$ & $(0.126)$ & $(0.129)$ & $(0.149)$ & $(0.154)$ & $(0.138)$ \\
\hline \multirow[t]{2}{*}{ Constant } & $-5.167^{* *}$ & $-4.283^{*}$ & $-3.988^{*}$ & -5.285 & -5.286 & $-8.663^{* *}$ \\
\hline & $(1.110)$ & $(1.766)$ & $(1.798)$ & $(2.742)$ & $(2.771)$ & $(2.620)$ \\
\hline Observations & 86 & 86 & 86 & 69 & 69 & 64 \\
\hline R-squared & 0.48 & 0.48 & 0.48 & 0.66 & 0.66 & 0.75 \\
\hline
\end{tabular}

Robust standard errors in parentheses, * significant at $5 \%$; ** significant at $1 \%$

\section{Notes:}

The dependent variable differs from Table 2 in that it only includes imports by U.S. affiliates from their foreign parents. Except for Variety Residual, which is the residual from the gravity equation in column (1) of Table 1 , all the other explanatory variables are the same as in Antràs (2003). 


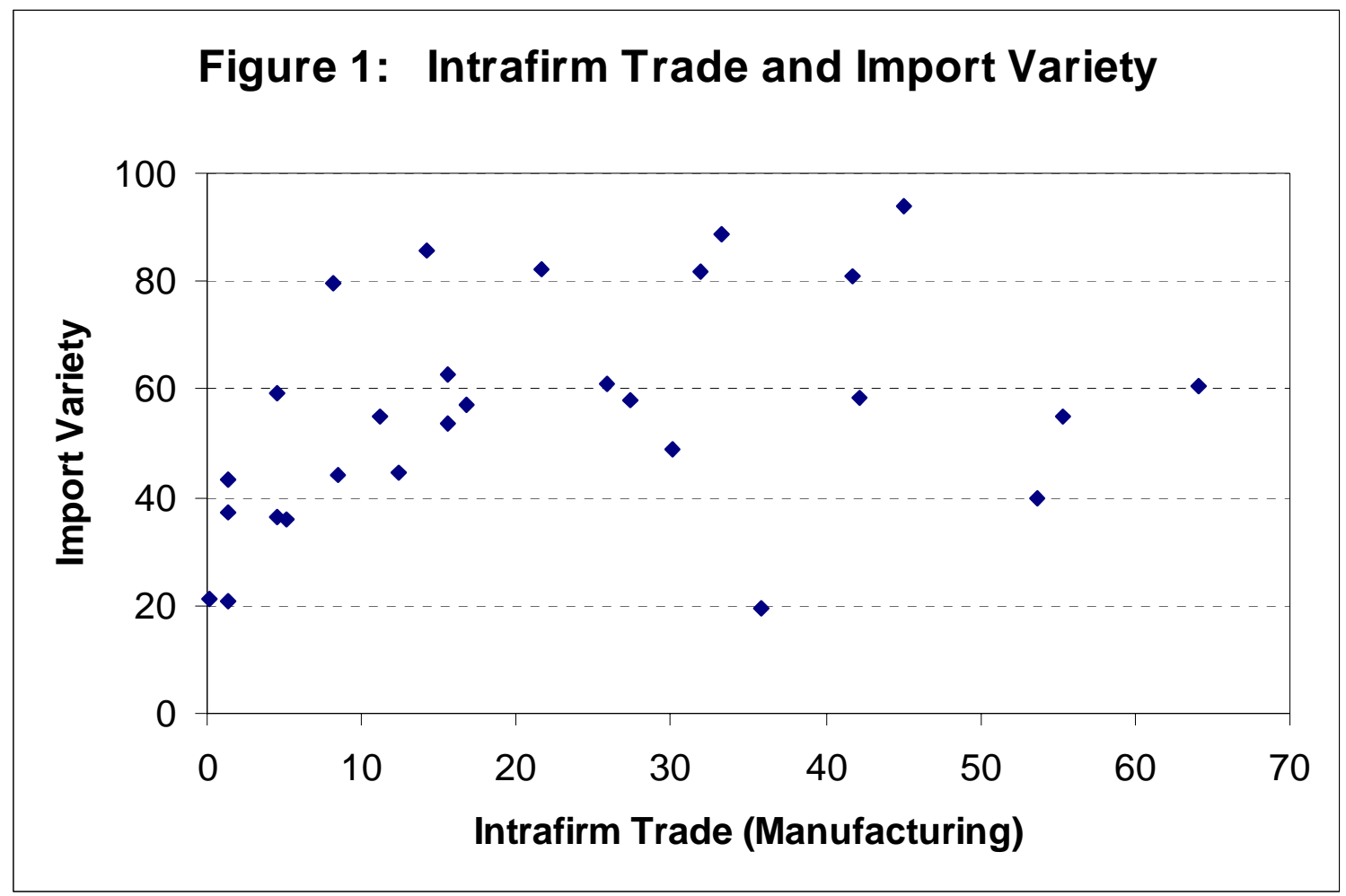

Figure 2: Intrafirm Trade and Variety Residual

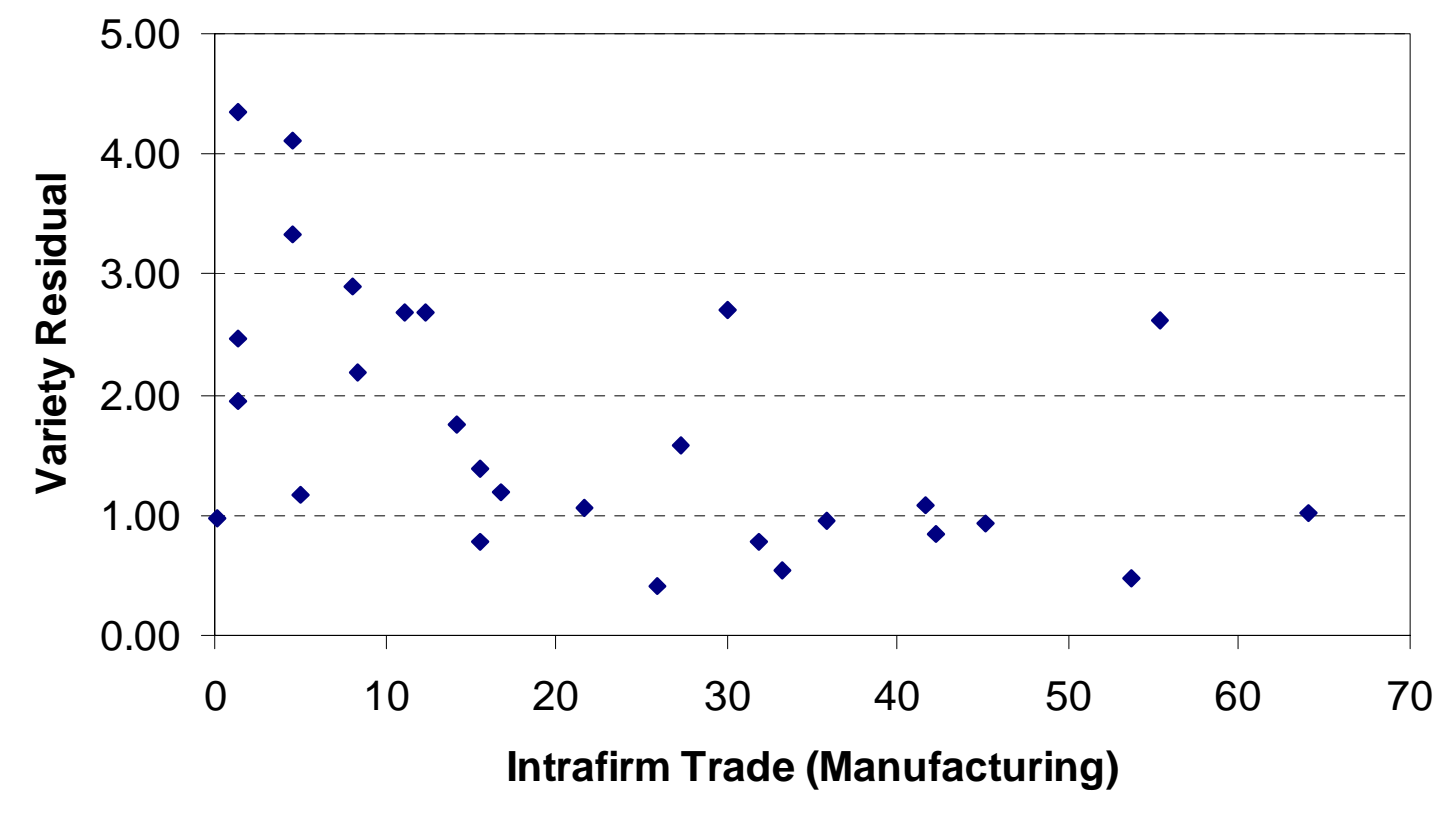

